\title{
Compassionate aortic valve implantation for severe aortic regurgitation
}

\author{
Gregory Ducrocq, MD, Dominique Himbert, MD, Ulrik Hvass, MD, and Alec Vahanian, MD, Paris, France
}

We report the case of a young woman with severe rheumatic aortic insufficiency who was treated by transcatheter aortic valve implantation (TAVI) because of contraindication to conventional valve replacement. The questions raised by this case are discussed.

\section{CLINICAL SUMMARY}

A 36 year-old woman was admitted to our department for worsening dyspnea (New York Heart Association class III) caused by severe aortic regurgitation (AR). Her medical history included rheumatic heart disease and a breast cancer

From the AP-HP, Bichat-Claude Bernard Hospital, Paris, France. Disclosures: None

Received for publication Dec 10, 2009; revisions received Jan 12, 2010; accepted for publication Feb 1, 2010; available ahead of print April 12, 2010.

Address for reprints: Dominique Himbert, MD, AP-HP, Bichat-Claude Bernard Hospital, Department of Cardiology, 46 rue Henri Huchard 75018 Paris, France (E-mail: dominique.himbert@bch.aphp.fr).

J Thorac Cardiovasc Surg 2010;140:930-2

$0022-5223 / \$ 36.00$

Copyright (c) 2010 by The American Association for Thoracic Surgery doi:10.1016/j.jtcvs.2010.02.003 treated with mastectomy and chest radiation in 2007 that was recently complicated by sternal metastases.

On admission, the patient was in good general condition, with a blood pressure of $100 / 50 \mathrm{~mm} \mathrm{Hg}$, and clinical signs of severe AR were present. Electrocardiographic analysis showed left ventricular (LV) hypertrophy and incomplete right bundle branch block. Transthoracic echocardiographic analysis confirmed the severity of the AR: regurgitant orifice area, $0.40 \mathrm{~cm}^{2}$; regurgitant volume, $75 \mathrm{~mL}$ (Figure 1, B); LV dilatation; end-systolic diameter, $49 \mathrm{~mm}$; and decreased ejection fraction (45\%). AR was of rheumatic cause, with mild calcifications, and was associated with a mild mitral regurgitation (regurgitant orifice area, $0.10 \mathrm{~cm}^{2}$; regurgitant volume, $11 \mathrm{~mL}$ ). The diameter of the aortic annulus was $24 \mathrm{~mm}$. The ascending aorta was moderately dilated (40 $\mathrm{mm}$ ). Systolic pulmonary artery pressure was $60 \mathrm{~mm} \mathrm{Hg}$. Supra-aortic angiographic analysis showed a grade 3 AR (Figure 1, A), and results of coronary angiographic analysis were normal. A multidisciplinary discussion with oncologists and cardiac surgeons led to the conclusion that life expectancy was approximately 2 years and the surgical risk of aortic valve replacement was exceedingly high because of

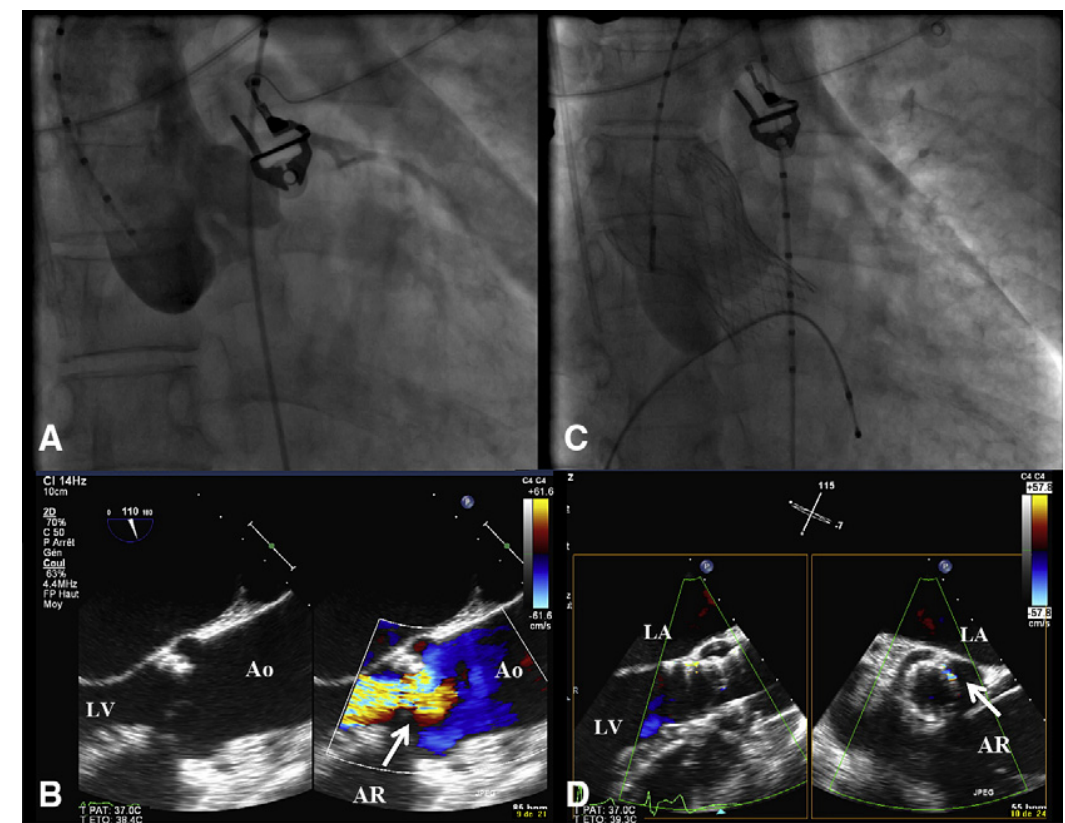

FIGURE 1. Severe aortic regurgitation $(A R)$ as observed by means of preprocedure supra-aortic angiographic (A) and transthoracic echocardiographic (B) analysis caused by rheumatic aortic valve disease. Postimplantation angiographic $(\mathrm{C})$ and transthoracic echocardiographic (D) analysis showed the good position of the CoreValve System and trivial paraprosthetic leak. $L V$, Left ventricle; $A o$, aorta; $L A$, left atrium. 


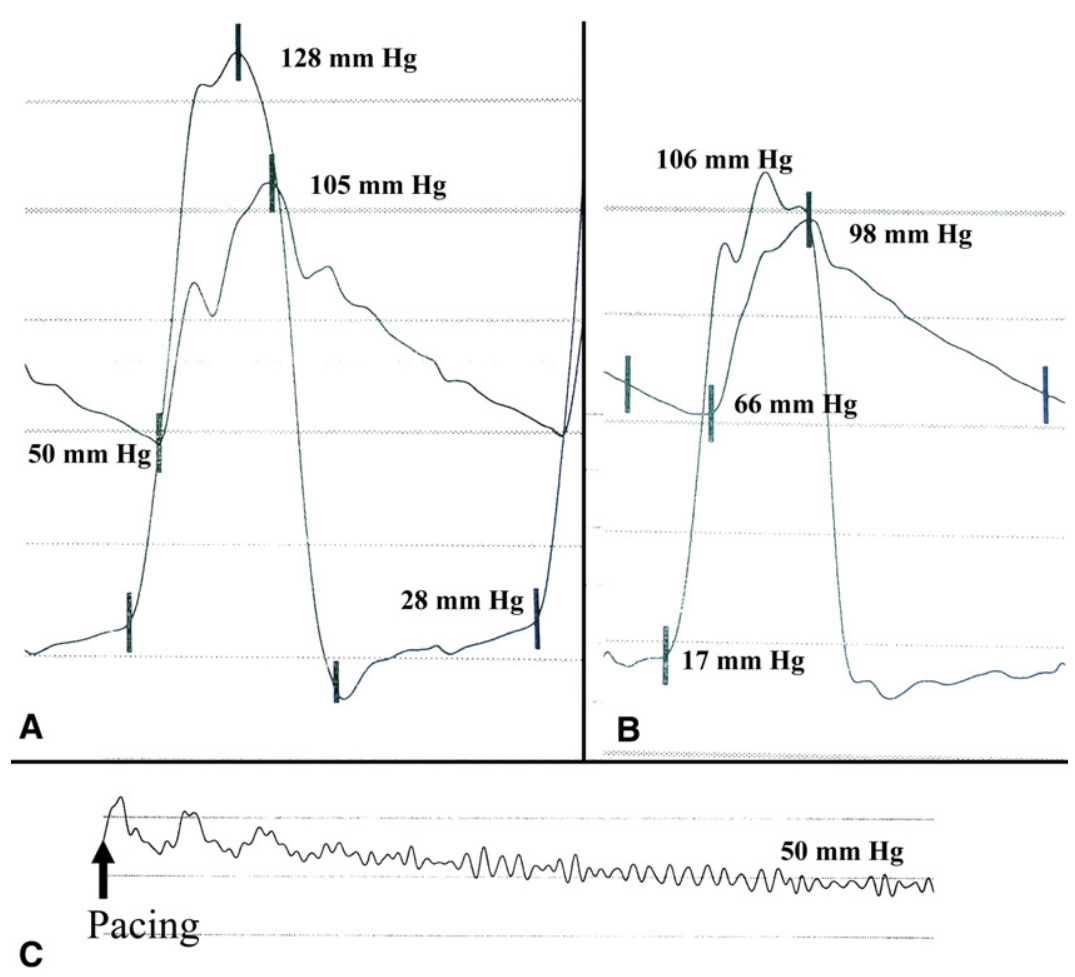

FIGURE 2. Invasive hemodynamic findings before (A) and after (B) CoreValve System implantation showing immediate decrease of left ventricular enddiastolic pressure and increase in diastolic aortic pressure after implantation. C, Aortic pressure during rapid ventricular pacing used for CoreValve System implantation.

mediastinal radiation and sternal metastases. Thus a compassionate TAVI was considered. After informed consent was obtained, a 29-mm Medtronic CoreValve System (Medtronic, Inc, Minneapolis, Minn) was implanted by means of percutaneous femoral access. Contrary to the usual technique in patients with aortic stenosis, balloon predilatation was not done, and rapid ventricular pacing was performed to stabilize the prosthesis during its implantation and avoid migration (Figure 2,C). In addition, continuous transesophageal echocardiographic (TEE) guidance was most useful for optimal positioning, which was rendered difficult by the absence of valve calcification serving as a landmark. After implantation, dilatation with a 25 -mm-diameter balloon was necessary to obtain an adequate deployment of the prosthesis. TEE and supra-aortic angiographic analysis showed its good position and a trivial residual AR (Figure 1,C). The mean gradient decreased from $25 \mathrm{~mm} \mathrm{Hg}$ before implantation to $8 \mathrm{~mm} \mathrm{Hg}$, and LV end-diastolic pressure decreased from 28 to $17 \mathrm{~mm} \mathrm{Hg}$ (Figure 2, $A$ and $B$ ). Complete atrioventricular block occurred at day 3 and required permanent pacemaker implantation. In-hospital outcome was otherwise uneventful. Predischarge transthoracic echocardiographic analysis showed a circular shape of the prosthesis, with no significant impairment of the mitral valve, a trivial intraprosthetic AR and a grade 1/4 internal paraprosthetic AR (Figure 1,D). The patient was discharged at day 12 in New York Heart Association class I.

\section{DISCUSSION}

To date, the only admitted indication for TAVI is the treatment of patients with severe symptomatic aortic stenosis and high risk for, or contraindications to, aortic valve replacement. ${ }^{1}$ This indication has given satisfactory survival and functional results up to 3 years. However, preliminary reports suggested feasibility and good short-term results with "off-label" uses of TAVI, the first of which being treatment of degenerated aortic bioprostheses..$^{2-4}$

To our knowledge, this is the first report of TAVI to treat severe AR in a native valve, and it raises 3 main questions. The first relates to the clinical context that led to this decision. In addition to her cancer, this young and still very active woman was severely and increasingly disabled by her valve disease, and comprehensive multidisciplinary evaluation precluded any surgical options. Although her life expectancy was probably limited, it was estimated to be at least around 2 years. Thus it was mandatory to find an alternative to improve her quality of life.

The second question relates to the technical aspects of prosthesis implantation. Hyperkinetic cardiac motion caused by AR and absence of angiographic landmarks increased the risks of misplacement and migration of the prosthesis. This report shows that they could be effectively managed by using careful fluoroscopic and TEE guidance and rapid ventricular pacing. Finally, TAVI was technically feasible because the AR was of rheumatic and not 
dystrophic nature, with no severe dilatation of the aortic root.

The third question relates to the risk of complete atrioventricular block after CoreValve System implantation. Several predictors, including pre-existing right bundle branch block, have been determined and should lead to careful and prolonged predischarge monitoring, all the more because these conduction disturbances can be delayed, as was the case in the present report. ${ }^{5}$

In the future, the treatment of AR by means of TAVI will probably remain restricted to very particular and individual cases but might be life-saving or contribute to an improvement in the functional status of patients with no other therapeutic options.

\section{References}

1. Vahanian A, Alfieri O, Al-Attar N, Antunes MJ, Bax J, Cormier B, et al. Transcatheter valve implantation for patients with aortic stenosis: a position statement from the European Association of Cardio-Thoracic Surgery (EACTS) and the European Society of Cardiology (ESC), in collaboration with the European Association of Percutaneous Cardiovascular Interventions (EAPCI). Eur Heart J. 2008;29:1463-70.

2. Walther T, Falk V, Dewey T, Kempfert J, Emrich F, Pfannmuller B, et al. Valve-invalve concept for transcatheter minimally invasive repeat xenograft implantation. J Am Coll Cardiol. 2007;50:56-60.

3. Wenaweser P, Buellesfeld J, Gerckens U, Grube E. Percutaneous aortic valve replacement for severe aortic regurgitation in degenerated bioprosthesis: the first valve in valve procedure using the CoreValve Revalving System. Catheter Cardiovasc Interv. 2007;70:760-4.

4. Attias D, Himbert D, Hvass U, Vahanian A. "Valve-in-valve" implantation in a patient with stentless bioprosthesis and severe intraprosthetic aortic regurgitation. J Thorac Cardiovasc Surg. 2009;138:102-2.

5. Piazza N, Nuis RJ, Tzikas A, Schultz C, Onuma Y, Otten A, et al. Persistent conduction abnormalities and requirements for pacemaking 6 months after transcatheter aortic valve implantation. Circulation. 2009;120(suppl):S949-50.

\title{
Less invasive left ventricular assist device placement for difficult resternotomy
}

\author{
Hiroo Takayama, MD, ${ }^{\text {a }}$ Yoshifumi Naka, MD, PhD, ${ }^{\mathrm{a}}$ Ulrich P. Jorde, MD, ${ }^{\mathrm{b}}$ and Allan S. Stewart, MD, ${ }^{\mathrm{a}}$
} New York, NY

Left ventricular assist devices (LVADs) are playing an increasingly important role in the management of end-stage heart failure, especially with the advances in technology in implantable LVADs. Placement of an implantable LVAD generally requires a median sternotomy, and this approach might not be suitable for unstable patients with difficult resternotomy. Even in such a situation, however, current state-of-the-art technology can provide mechanical circulatory support either with extracorporeal membrane oxygenation (ECMO) or, more recently, with percutaneous LVADs. ${ }^{1,2}$ The shortcoming of the latter modalities is that they are not designed for prolonged periods of support. Here we describe a unique configuration of the CentriMag LVAD (Thoratec Corp, Pleasanton, Calif) that allowed rapid off-pump placement of the device without performing a sternotomy.

\footnotetext{
From the Divisions of Cardiothoracic Surgery ${ }^{\mathrm{a}}$ and Cardiology, ${ }^{\mathrm{b}}$ Columbia University Medical Center, New York, NY.

Disclosures: None.

Received for publication March 8, 2010; revisions received April 14, 2010; accepted for publication April 26, 2010; available ahead of print June 11, 2010.

Address for reprints: Allan S. Stewart, MD, Columbia University Medical Center, Milstein Hospital Building, 7-435, 177 Fort Washington Ave, New York, NY 10032 (E-mail: as2276@columbia.edu).

J Thorac Cardiovasc Surg 2010;140:932-3

$0022-5223 / \$ 36.00$

Copyright (c) 2010 by The American Association for Thoracic Surgery doi:10.1016/j.jtcvs.2010.04.028
}

\section{CLINICAL SUMMARY}

The patient was a 50-year-old man (height, $180 \mathrm{~cm}$; weight, $105 \mathrm{~kg}$ ) with nonischemic dilated cardiomyopathy. He previously had 2 sternotomies; the first was an aortic valve replacement with a mechanical valve for congenital bicuspid aortic valve 8 years ago, and the second was a hemiarch repair of a type A aortic dissection 4 years ago. The patient first had symptoms of congestive heart failure (CHF) about 6 years ago, with recent progression requiring multiple hospitalizations, and was listed for heart transplantation. His condition recently further deteriorated, with acutely decompensated CHF and ventricular arrhythmia requiring admission to the intensive care unit. Although CHF improved with infusion of inotropic agents, ventricular arrhythmia persisted and became more frequent, with multiple firings of his implantable cardioverter defibrillator. Intra-aortic balloon pump therapy was not applicable because of the remaining aortic dissection in the descending aorta. At this point, urgent LVAD support was deemed necessary.

The patient was taken to the operating room. In the supine position general anesthesia was induced with a single-lumen endotracheal tube. The previous right axillary artery cannulation site was opened, and the artery was exposed. A left anterior minithoracotomy through the sixth intercostal space was performed, and the left ventricular apex was exposed by dissecting some loose adhesion inside of the pericardium. 